\title{
Common Health-Care Units in Industrial Parks in Taiwan
}

\author{
Shih-Bin Su ${ }^{1,2}$, How-Ran Guol and Po-Chang Huang ${ }^{1}$ \\ 'Graduate Institute of Environmental and Occupational Health, Medical College, National \\ Cheng Kung University and \\ 'Tainan Science-Based Industrial Park Clinic, Chi-Mei Foundation Hospital
}

\begin{abstract}
Common Health-Care Units in Industrial Parks in Taiwan: Shih-Bin Su, et al. Graduate Institute of Environmental and Occupational Health, Medical College, National Cheng Kung UniversityIn Taiwan, according to the Worker' Health Protection Regulation (the Regulation), factories with more than 300 employees in total or more than 100 employees engaged in specific hazardous tasks are required to establish on-site health-care units. In addition to general primary care, these units should serve eight specific functions, including health education and promotion, diagnosis and treatment of occupational diseases, vaccination, job placement, health examination, study of occupational health and maintenance of records of occupational diseases and injuries, prevention of occupational diseases and improvement of work environments, and family planning. Factories in the same industrial park are allowed to establish a common health-care unit instead of individual health-care units in the factories. We conducted a nationwide survey of the industrial parks and, through site visits, collected data on the pattern of organization, manpower, and services of their common health-care units with a standard questionnaire. We also evaluated their functions as set forth by the Regulation. As a result, we found only 10 of the $65(15.4 \%)$ industrial parks had common health-care units and obtained data on 8 . The variations in the pattern of organization, manpower, and services were quite large, but most of the units did not carry out all the eight essential functions. Because the establishment of a common health-care unit can save cost, it is planned by many industrial parks under construction. The results of our survey showed that these units may not function well, which calls for more thoughtful planning and proper law enforcement.
\end{abstract} (J Occup Health 2001; 43: 382-387)

Received April 23, 2001: Accepted Aug 27, 2001

Correspondence to: H.-R. Guo, Deparmem of Envirommental and Occupational Health. Medical College. National Cheng Kang University, 138 Sheng-Li Road, Tainan 70428, Taivan
Key words: Industrial park, Occupational health service, Delivery of health care, Health-care unit, Taiwan

In Taiwan, according to the Workers' Health Protection Regulation (the Regulation), factories with more than 300 employees in total or with more than 100 employees engaged in 11 specific hazardous lasks are required to establish on-site health-care units. According to the Regulation, these units should serve eight specific functions: ( 1 ) design and execute health education, health promotion, and health consultation programs for workers; (2) diagnose and treat occupational and non-occupational diseases as well as medical emergencies; (3) conduct vaccination and other discase prevention measures: (4) help the employers to select proper jobs for each employee; (5) carry out pre-employment and periodical health check-ups of workers; (6) study and report on issues related to occupational health and maintain records of occupational diseases and injuries; (7) assist the employers and industrial hygienists to prevent occupational diseases and improve work environments; and (8) offer workers family planning services". These health-care units are supposed to play a very important role in the protection of the health of the working population.

The Regulation also sets out the minimum requirements for manpower in terms of the numbers of physicians and nurses (Table 1). All the nurses need to be full-time staff, and a full-time physician can be substituted for by two part-time physicians. Moreover, factorics with more than 1,000 workers must have at least one full-time physician. The definition of a part-time physician varies according to the number of workers in the factory (Table 1).

Lnder a special provision of the Regulation, factories in an industrial park are allowed to establish a common health-care unit instead of individual health-care units in the factories, but the Regulation does not provide guidelines on the pattern of organization. Because the establishment of a common health-care unit is generally 
Table 1. Minimum manpower requirements of on-site health-care units under the Workers' Health Protection Law

\begin{tabular}{|c|c|c|}
\hline Number of workers & Physician $^{a}$ & Nurses \\
\hline $\begin{array}{l}\text { More than } 300 \text { in total or more than } \\
100 \text { with hazardous tasks, but less } \\
\text { than } 1,000 \text { in total }\end{array}$ & 1 part-time & 1 full-time \\
\hline 1,000 or more, but less than 3,000 & 1 full time & 2 full-time \\
\hline 3,000 or more, but less than 6,000 & 2 full time or 1 full-time and 2 part-time & 3 full-time \\
\hline \multirow[t]{2}{*}{6,000 or more } & $\begin{array}{l}2 \text { full-time and } 2 \text { part-time or } \\
1 \text { full-time and } 4 \text { part-time }\end{array}$ & 4 full-time \\
\hline & $\begin{array}{l}\text { additional } 1 \text { full-time or } 2 \\
\text { part-time for each } 5,000 \\
\text { increase in employees above } 6,000\end{array}$ & $\begin{array}{l}\text { additional } 1 \text { full-time for } \\
\text { each } 5,000 \text { increase in } \\
\text { employees above } 6,000\end{array}$ \\
\hline
\end{tabular}

"For factories with less than 300 workers but more than 100 engaged in the 11 specific hazardous tasks designated by law, a part-time physician should spend at least $4 \mathrm{~h}$ a week in the health-care unit; for those with 300 to 1,000 workers, a part-time physician should spend at least an additional $2 \mathrm{~h}$ a week for each 100 additional workers; and for those with more than 1,000 workers, a part-time physician should spend at least $18 \mathrm{~h}$ a week.

believed to be cost-effective and can save money for individual factories, it is planned by many industrial parks under construction. To get an overview of the current situation of the common health-care units in the industrial parks in Taiwan and evaluate their functions, we conducted a nationwide survey from 1999 to 2000.

\section{Materials and Methods}

In October 1999, we identified all the existing common health-care units in industrial parks by checking the websites of related government agencies and the directory of members of the Taiwan Medical Association. In Taiwan, joining the Association is mandatory for practicing medicine. There were a total of 65 industrial parks regulated by the central government, including 57 by the Bureau of Industry, 6 by the Economic Processing Zone Administration, and 2 by the National Science Council (NSC). The two regulated by the NSC were called science-based industrial parks. As a result, we found 10 common health-care units in the 65 industrial parks $(15.4 \%)$. Then we arranged a site visit to each unit.

The site visits were conducted from November 1999 to May 2000. A standard questionnaire was used to collected information on the industry park and the healthcare unit. The study staff filled out the questionnaire during the site visit, and the director of the unit was interviewed. Data collected on each industrial park included the number of factories and the total number of workers. From the health-care unit, we collected information on organization, management, manpower, equipment, financial status, and services in the one-year period before the site visit. The required numbers of doctors and nurses were also calculated according to the
Regulation.

In evaluating the performance of the eight essential functions designated by the Regulation, the criteria of minimum performance were defined as the following:

(1) Design and execute health education, health promotion, and health consultation programs for workers: At least one program every other month on average in the previous year.

(2) Diagnose and treat occupational and nonoccupational diseases as well as medical emergencies: Offer all three types of services.

(3) Conduct vaccination and other disease prevention measures: Offer adult routine health examination covered by the National Health Insurance Program and at least one kind of vaccination.

(4) Help the employers to select a proper job for each employee: Offer such a service.

(5) Carry out pre-employment and periodical health check-ups of workers: Offer both services.

(6) Study and report issues related to occupational health and maintain records of occupational diseases and injuries: Maintain records of occupational diseases and injuries.

(7) Assist the employers and industrial hygienists to prevent occupational diseases and improve work environments: Made at least one suggestion on the prevention of occupational diseases or improvement of work environments in the past year.

(8) Offer workers family planning services: Offer family planning consultation and provide condoms or contraceptives.

The performance was evaluated on a dichotomous scale: whether the unit provided the service (had the function) or not. Therefore, the evaluation only 
Table 2. Size of the industrial park and manpower of the health-care units

\begin{tabular}{|c|c|c|c|c|c|c|c|c|}
\hline Characteristics & A & B & $\mathrm{C}$ & $\mathrm{D}$ & $\mathrm{E}$ & $\mathrm{F}$ & $\mathrm{G}$ & $\mathrm{H}$ \\
\hline Factories & 87 & 84 & 287 & 35 & 315 & 450 & 810 & 296 \\
\hline Workers & 16,778 & 33,290 & 80,000 & 15,573 & 25,000 & 25,000 & 30,000 & 25,000 \\
\hline \multicolumn{9}{|l|}{ Physicians appointed } \\
\hline Full-time & 2 & 1 & 1 & 1 & 1 & 1 & 1 & 1 \\
\hline Part-time & 9 & 5 & 3 & 5 & 0 & 0 & 1 & 3 \\
\hline Part-time physicians requireda & 6 & 14 & 32 & 6 & 10 & 10 & 12 & 10 \\
\hline Nurses appointed & 6 & 6 & 5 & 3 & 3 & 1 & 1 & 1 \\
\hline Nurses required & 6 & 9 & 18 & 5 & 7 & 7 & 8 & 7 \\
\hline Medical technician & 1 & 1 & 1 & 1 & 0 & 0 & 1 & 0 \\
\hline Pharmacist & 2 & 2 & 1 & 1 & 0 & 0 & 1 & 0 \\
\hline Radiology technician & 1 & 1 & 1 & 1 & 0 & 0 & 0 & 0 \\
\hline Administrative & 3 & 5 & 1 & 2 & 0 & 0 & 2 & 1 \\
\hline Part time paramedical personnel & 0 & 0 & 4 & 0 & 0 & 0 & 0 & 0 \\
\hline Fulfill personnel requirements & Yes & No & No & No & No & No & No & No \\
\hline
\end{tabular}

aCalculated on the basis of full-time physicians appointed.

Table 3. Organization and management of the health-care units

\begin{tabular}{|c|c|c|c|c|c|c|c|c|}
\hline Characteristics & A & B & $\mathrm{C}$ & $\mathrm{D}$ & E & F & G & $\mathrm{H}$ \\
\hline Ownership & Govemment & Government & Government & Government & Government & Government & Government & Private \\
\hline Management & Govemment & Government & Govemment & Government & Physician & Physician & Physician & Hospital \\
\hline Government pays debts & Fully & Fully & Partially & Partially & None & None & None & None \\
\hline Contract with employers & Yes & Yes & Yes & Yes & No & No & Yes & No \\
\hline Service fee per capita (NTD) & 25 & 25 & 30 & 25 & 0 & 0 & 0 & 0 \\
\hline Making a profit & No & No & Yes & No & $\mathrm{No}^{\mathrm{a}}$ & $\mathrm{No}^{\mathrm{a}}$ & $\mathrm{No}^{\mathrm{a}}$ & Unknown \\
\hline
\end{tabular}

No actual documentation was provided.

determined whether the unit met the minimum requirements. This approach was applied because the number of factories in each park varied a lot and the record keeping was poor in most units; it is difficult to conduct further evaluations.

According to the regulations, the lands in industrial parks are restricted to industrial use, and so there is no hospital or clinic other than the common health-care units in these industrial parks.

\section{Results}

Among the 10 common health-care units, 6 were in the 57 industrial parks regulated by the Bureau of Industry, 3 were in the 6 regulated by the Economic Processing Zone Administration, and 1 was in the 2 regulated by the National Science Council. The industrial parks regulated by the Bureau of Industry had a significantly lower proportion establishing a common health-care unit ( $p=0.02$ for Fisher's exact test). During our study period, two of the ten units went out of business before we could conduct the site visit. All the rest of the units participated in our survey, and they are referred to as units $\mathrm{A}, \mathrm{B}, \mathrm{C}, \mathrm{D}, \mathrm{E}, \mathrm{F}, \mathrm{G}$, and $\mathrm{H}$ according to the order of site visits. The eight participating units served a total of 2,364 factories with a total of about 250,000 workers. The average number of workers served by a common health-care unit was around 31,300 (Table 2).

The government owned seven of the units (all except $\mathrm{H}$ ) but managed only four (A, B, C, and D) (Table 3 ). If the unit is in debt at the end of the fiscal year, the government will cover the debts fully for two (A and B) and partially for two (C and D). The other three government-owned units were rented to and managed by the physician in charge (E, F, and $G$ ). The only nongovernment-owned unit (H) was jointly established by the employers in the park and managed by a small local hospital. The latter four units did not receive financial support from the government. Five of the units (A, B, C, $D$, and $G$ ) signed a contract with each of the employers in the park, and four of them charged a service fee on each worker (25 New Taiwan Dollars [NTD] for A, B, and $\mathrm{D}$, and $30 \mathrm{NTD}$ for $\mathrm{C}$; the exchange rate between 
Table 4. Functions of the health-care units

\begin{tabular}{|c|c|c|c|c|c|c|c|c|}
\hline Functions & A & B & $\mathrm{C}$ & $\mathrm{D}$ & E & $\mathrm{F}$ & $\mathrm{G}$ & $\mathrm{H}$ \\
\hline $\begin{array}{l}\text { Design and execute health education, health promotion, and health } \\
\text { consultation programs for workers }\end{array}$ & Yes & No & Yes & Yes & No & No & Yes & No \\
\hline $\begin{array}{l}\text { Diagnose and treat occupational and non-occupational diseases as well as } \\
\text { medical emergencies }\end{array}$ & Yes & Yes & Yes & Yes & Yes & Yes & Yes & Yes \\
\hline Conduct vaccination and other disease prevention measures & Yes & Yes & Yes & Yes & No & No & No & Yes \\
\hline Help the employers to select a proper job for each employee & Yes & Yes & Yes & Yes & No & No & Yes & No \\
\hline Carry out pre-employment and periodical health check-ups of workers & Yes & Yes & Yes & Yes & No & No & No & No \\
\hline $\begin{array}{l}\text { Study and report on issues related to occupational health and maintain } \\
\text { records of occupational diseases and injuries }\end{array}$ & Yes & Yes & No & Yes & No & No & Yes & No \\
\hline $\begin{array}{l}\text { Assist the employers and industrial hygienists to prevent occupational } \\
\text { diseases and improve work environments }\end{array}$ & Yes & Yes & Yes & Yes & No & No & No & No \\
\hline Offer workers family planning services & Yes & Yes & Yes & Yes & No & No & No & No \\
\hline Proportion of the 8 functions with minimum performance at least & $8 / 8$ & $7 / 8$ & $7 / 8$ & $8 / 8$ & $1 / 8$ & $1 / 8$ & $4 / 8$ & $2 / 8$ \\
\hline
\end{tabular}

U.S. Dollar and NTD was around 1 to 31 when the survey was conducted). Unit $\mathrm{G}$ did not sign such a contract but offered a discount card for each worker in the industrial park. Among the four that could receive financial support from the government, three (A, B, and D) were in debt. For the other four units, the exact balance was not available and hard to calculate, but we were told by all three of the physicians in charge that if the physicians had received only the average salary of other physicians in Taiwan, the units would be in debt.

All eight units had at least one full-time physician and one full-time nurse, and except for Unit F, they have at least one additional staff member (Table 2), but only one (Unit A) had more than one full-time physician, and this unit was the only one that fulfilled the government's personnel requirements. The other seven units could meet the requirements for neither physicians nor nurses. When two part-time physicians were counted as one physician, the overall physician to worker ratio was about 1 to 11,600. All the nurses were full-time, and the nurse to worker ratio was about 1 to 7,000 on average.

Only a half of the eight units (A, B, C, and D) had the function of "design and execute health education, health promotion, and health consultation programs for workers" (Table 4). The programs most frequently offered were first-aid courses. All units offered the service of "diagnose and treat occupational and non-occupational diseases as well as medical emergencies," but two (E and F) did not diagnose any case of occupational disease in the previous year. Five units (A, B, C, D, and $\mathrm{H}$ ) conducted vaccination and adult routine health examinations. Among the rest, one did not offer adult routine health examination (E), one did not provide vaccination services $(\mathrm{G})$, and one provided neither of these $(\mathrm{F})$. Of the eight units, five ( $A, B, C, D$, and $G$ ) offered help to the employers to select a proper job for each employee, and a half (A, B, C, and D) carried out both pre-employment and periodical health check-ups of workers. Four of the units $(\mathrm{C}, \mathrm{E}, \mathrm{F}$, and $\mathrm{H})$ did not maintain records of occupational diseases and injuries, and four $(E, F, G$, and $\mathrm{H})$ did not provide any suggestion on the prevention of occupational diseases or improvement of work environments in the previous year. Unit $C$ made ten such suggestions, D made two, and A and B made one only. A half of the units ( $A, B, C$, and D) offered family planning consultation and provided condoms, and unit $\mathrm{C}$ also provided oral contraceptives.

\section{Discussion}

In comparison with establishing individual health-care units, establishing a common health-care unit in an industrial park in Taiwan has at least the following advantages:

1. Consolidate the resources to achieve costeffectiveness and lower the cost of individual employers.

2. Meet the requirements of the Regulation more easily.

3. Can serve small factories (less than 300 workers) in the same park.

4. May employ professionals to manage the health-care unit to relieve the administrative burden and troubles of the employers.

5. Provide a mechanism to manage the safety and health of the park as a whole.

6. Be able to upgrade the equipment and broaden the specialties of the personnel and thus to provide better and more comprehensive services.

7. Have the potential of serving the needs of residents 
living around the park and making a profit.

Nonetheless, the survey showed that only a small portion of the industrial parks in Taiwan took advantage of the special provision of the Regulation. The major reason is that the Regulation has not been strictly enforced, and thus employers have no incentive to establish such units unless the units themselves are profitable or the employers really care about the safety and health of the their employees. From our survey, we found almost all of the common health-care units were not making a profit. This might be the reason why most of the units were owned by the government. A nationwide survey showed that nearly 800 factories and industrial parks in Taiwan should establish a health-care unit according to the Regulation, but less then $30 \%$ of them $\operatorname{did}^{2)}$.

Our survey showed that all except one unit had only one full-time physician. In general, hiring two part-time physicians costs less than hiring one full-time physician. This cost-cutting measure is not against the Regulation. Even with this measure, however, only one of the units could fulfill the personnel requirements. Whereas the Regulation does not set out requirements for other personnel (Table 2), it is required to have at least one medical technician and one radiology technician to conduct regular health check-ups of workers. In addition, a pharmacist is required if the unit offers prescription drugs. Therefore, there is no way for the other seven units to shift the salary for hiring other staff to hire additional physicians and nurses with the current personnel budget to meet the personnel requirements of the Regulation.

Form the site visits, we found that only two of the eight units (25\%) could carry out all eight essential functions satisfactorily and that another two could carry out only one. The only function that all eight units could cover was "diagnose and treat occupational and nonoccupational diseases as well as medical emergencies," which indicated the main purpose for establishing the unit was for primary health-care. The fact that two of them did not diagnose any case of occupational disease in the previous year was not really surprising, although it is hard to believe that not a single case occurred in either of these industrial parks during the one-year period before the site visit. The Regulation does not require the employer to have an occupational medicine specialist, so that the physicians taking care of the health units did not necessarily have the ability to diagnose occupational diseases. Therefore, three of the units could not provide any of the other four functions that generally require further training in occupational medicine ("help the employers to select a proper job for each employee," "carried out both pre-employment and periodical health check-ups of workers," "study and report issues related to occupational health and maintain records of occupational diseases and injuries," and "provide suggestions on the prevention of occupational diseases or improvement of work environments"). In fact, none of the physicians in these eight units had board certification in occupation medicine, and therefore even though they provided some of the services related to occupational medicine, they might not be able to do the function well. In order to do all eight essential functions well, each health-unit should have at least one occupational medicine specialist.

There are, of course, some drawbacks to establishing a common health-care unit in the industrial park in comparison with establishing individual health-care units, which include at least the following:

I. Inconvenience to the factories that are far away from the unit in the park.

2. Difficultics in managing a relatively large unit.

3. Inability to serve some special needs of individual factories.

Having a shuttle bus or other means of transportation can solve the first problem, but that will add costs. An alternative is to have scheduled visits by the physician to those factories. The second can be solved by hiring professionals to manage the unit. In fact, it may cost more for individual factories to hire professional managers or to not hire such managers at all. Factories with special needs can still hire additional professional on their own and have the common health-care units meet their general needs. Nonetheless, these drawbacks were not actually the main reasons why the industrial parks did not have common health-care units, because only a very small proportion of the factories in industrial parks without common health-care units really established a health-care unit of their own ${ }^{2)}$. The main problems are law enforcement and costs.

Stringent law enforcement is an obvious way to solve the problem, but not the best one. A better way is to make the unit profitable or at least cost much less. From our survey, we know a service fee of 30 NTD per person per month should be able to cover the costs (as in Unit C). Nonetheless, that still adds to the costs paid by employers. Although it seems unlikely that a population of 31,300 (the average size of the population served by each unit) does not need a single health-care unit, it should be noted that workers are among the most healthy in the whole population. Furthermore, Taiwanese workers generally try not to take sick leave to see a doctor unless the illness really bothers them, and for many workers in an industrial park, the breaks during the working hours are usually not long enough to take a round trip to a healthcare unit outside the factory. Therefore, a common healthcare unit that provides general primary care exclusively might not be able to survive. The income from health examinations (including pre-employment and periodical check-ups of workers as well as the routine health check- 
up offered by the National Insurance Program) may help, but more equipment and personnel are needed, which might not be cost-beneficial.

During our study period, a new common health-care unit was established in the other science-based industrial park. This park applied a different approach - calling in a large medical center to establish the unit in the park on the medical center's cost and management and having employers sign a contract to pay a monthly fee of 50 NTD for each worker. The "hospital-based group health service" model seems to be a promising solution for the following reasons at least:

1. No initial capital investment from the employers.

2. Consolidation of the supplies (including medication) with the large demands of the medical center to lower the costs.

3. Management by highly qualified professionals.

4. Using the medical center as a backup for referrals and providing a wide variety of services that can meet many special needs of individual employers.

5. Consolidation of the needs for equipment and laboratory tests with the medical center to lower the costs.

6. Attracting residents living around the park to use the services and thus making a profit to balance the costs.

Further follow-up of this unit is needed to evaluate whether this approach can work better.

The establishment of common health-care units in industrial parks has a long history in Taiwan since $1968^{33}$, but very few studies have been conducted ${ }^{3.4}$. We used "industrial park," "industrial parks," "industrial area," "industrial areas," "industrial region," "industrial regions," "industrial district," and "industrial districts" combined with "occupational health services," "delivery of health care," "health care," and "health-care" as the key words to conduct a search in the Medline but find little English literature on this issue ${ }^{5}$. There is no doubt that establishing a common health-care unit is more costeffective than establishing many individual units in the factories in the same industrial park, and therefore many industrial parks that are still in planning adopt the approach. This paper has summarized the experience that can be used as references for these parks. Furthermore, other countries might also benefit from the experience in Taiwan.

Acknowledgment: This study was supported by Grant DOH89-TD-1164 from the Department of Health of Taiwan. The authors would also like to thank the eight participating health-care units for their cooperation.

\section{References}

1) Council of Labor Affairs. Collection of Occupational Safety and Health Regulations, Vol. 3. Taipei: R.O.C. Council of Labor Affairs; 1999.

2) Institute of Occupational Safety and Health. Annual Report of Occupational Safety and Health, 1998. Taipei: R.O.C. Council of Labor Affairs; 1999.

3) Wang L-J. Establishing health-care units in industrial parks. Ind Safety Health Monthly 1973; 9: 18-25.

4) Wang L-J. Study of the establishment of common health-care units in industrial parks. Economic Processing Zone Newsletter 1973; 8: 14-22.

5) Pines A, Alkaslassy D, Furth JM, Lemesch C. A pilot occupational health service for small enterprises: first year experience - the Givat Shaul project. Israel J Med Sci 1992; 28: 659-666. 